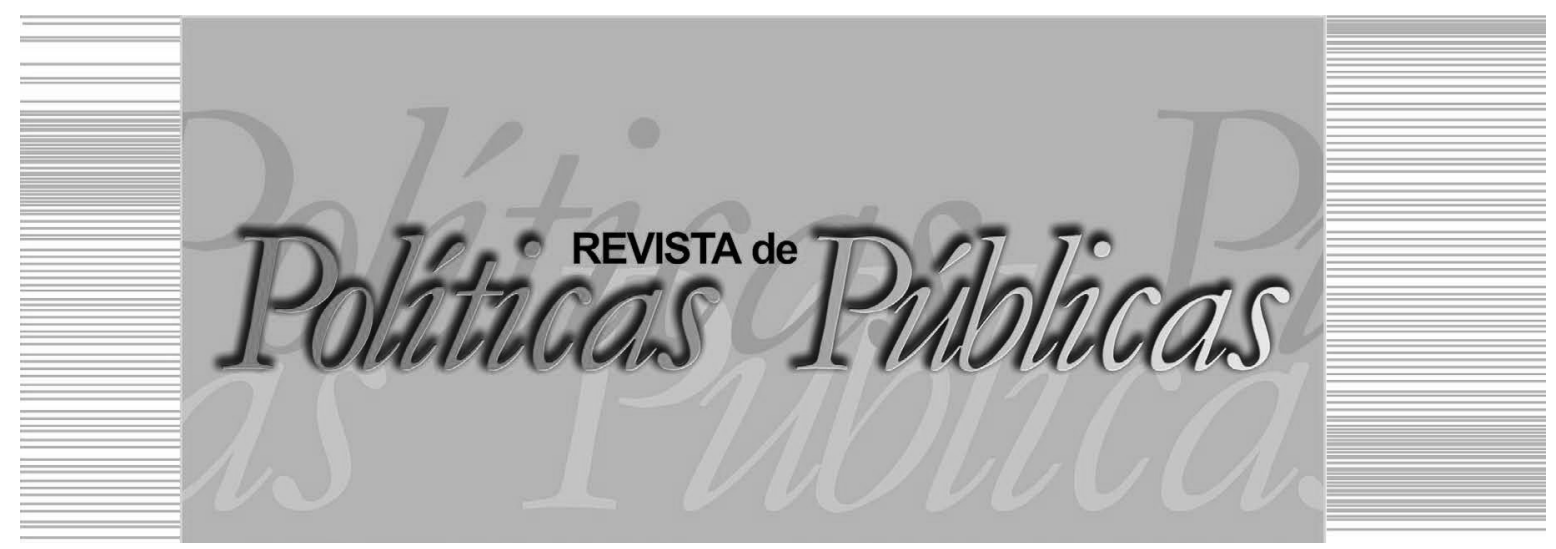

\title{
ANÁLISE DA GESTÃO HÍDRICA EM SÃO PAULO À LUZ DO REFERENCIAL DE JOAN SUBIRATS
}

Guilherme Barbosa Checco ${ }^{I}$

\section{Resumo}

Este artigo pretende rever os acontecimentos relacionados à crise hídrica em São Paulo durante os anos de 2014 e 2015 a partir do aporte teórico de Joan Subirats. Para tanto, analisa discursos de atores atrelados ao governo estadual com importante papel na gestão da água. O objetivo é de, ao analisar os discursos do Governador do Estado, do Secretário de Saneamento e Recursos Hídricos e do Presidente da Sabesp, a partir do aporte teórico de Joan Subirats, verificar se é possível afirmar que a gestão dos recursos hídricos em São Paulo se tornou um problema de política pública. Reconhecendo que o governo estadual não é o único ente e ator responsável pela governança dos recursos hídricos em São Paulo, a proposta é desenvolver uma possível narrativa que explique como a situação está sendo gerida por um importante ator do Sistema Nacional de Gerenciamento dos Recursos Hídricos.

Palavras-chave: Crise hídrica, Governo Estadual de São Paulo, políticas públicas, Joan Subirats

\footnotetext{
Bacharel em Relações Internacionais, Mestrando em Ciência Ambiental pelo Instituto de Energia e Ambiente (IEE) da Universidade de São Paulo (USP) e Pesquisador no Instituto Democracia e Sustentabilidade (IDS). E-mail: guichecco@hotmail.com / Universidade de São Paulo - USP: Avenida Professor Luciano Gualberto, 1289, Cidade Universitária, Butantã - São Paulo SP. CEP: 05508-010.
} 


\title{
ANALYSIS OF THE HYDRIC MANAGEMENT IN SÃO PAULO UNDER THE THEORETICAL REFERENCE OF JOAN SUBIRATS
}

\begin{abstract}
This article intends to review the events related to the hydric crisis in São Paulo during the years of 2014 and 2015 based on the theoretical contribution of Joan Subirats. Therefore analyzes some speeches from actors related to the state government and with an important role in the management of water. The purpose is to, by analyzing the speeches of the Governor, the Secretary of Sanitation and the Sabesp's President, considering the theoretical referential from Joan Subirats, verify if it is possible to claim that the management of the hydric resources in São Paulo has become a political policy problem. Considering that the state government is not the only responsible for the governance of hydric resources in São Paulo, the goal is to develop a possible narrative that explains how the situation has been managed by an important actor of the National System of Management of Hydric Resources.

Key words: Hydric crisis, state government of São Paulo, public policies,
\end{abstract} Joan Subirats.

\section{INTRODUÇÃO}

Existe há algum tempo alertas científicos de que a região de São Paulo passaria por esse período de baixos índices pluviométricos, ou seja, com pouca chuva. Esses alertas chegaram ao conhecimento dos gestores públicos e inclusive da própria sociedade em geral, por meio da veiculação de notícias na mídia com importante capilaridade.

O cruzamento de duas informações importantes permite verificar possibilidades de momentos em que essa narrativa de crise hídrica começa a ser traçada. No ano de 2011, a Companhia de Saneamento Básico do Estado de São Paulo (Sabesp) elaborou um relatório no qual estava impressa a informação de que havia um déficit de 1500 litros de água por segundo entre a demanda e a capacidade de oferta dos sistemas de abastecimento da Região Metropolitana de São Paulo (RMSP). Neste mesmo ano, o Sistema Cantareira, principal manancial de abastecimento da RMSP, estava com as capacidades de 74,9\% e 67,2\% (COMPANHIA DE SANEAMENTO BÁSICO DO ESTADO DE SÃO PAULO, 2003), no inicio e ao final do ano, respectivamente. Quatro anos depois, o mesmo Sistema Cantareira conta atualmente com índices negativos de reserva d'água. 
Os baixos índices de precipitação, somados à falta de planejamento estratégico com ações de adaptação para esse cenário previsto com certa antecedência, representaram importantes causas da crise na governança hídrica. A partir dos primeiros meses de 2014 verifica-se que essa temática ganha espaço nos noticiários nacionais, dando maior notoriedade a um problema que vinha sendo construído pelo menos há três anos. Já em janeiro de 2014 o Sistema Cantareira contava com a capacidade abaixo de $27 \%$, tendência acompanhada pelos outros sistemas de abastecimento, situação que contribuiu para que o contexto de crise hídrica ganhasse relevância no debate público, na veiculação das informações e na certa preocupação dos tomadores de decisão.

Essa conjuntura contribuiu para que o tema entrasse na pauta do debate público. Não obstante, os discursos dos gestores públicos eram pouco esclarecedores e pareciam não considerar os alertas para a gravidade da situação. Notadamente, as eleições em nível federal e estadual no País, que aconteceriam em outubro de 2014, representam importante variável que auxilia a leitura.

Nota-se que a resposta dos gestores públicos à situação concentrou-se em ações de curto prazo, com foco principal em ações como obras para captação de água e interligação dos sistemas e a diminuição na pressão das tubulações. Durante o transcorrer do período algumas outras políticas tópicas foram implementadas, como por exemplo, as multas por consumo excessivo e os descontos nas tarifas dos consumidores que o diminuíssem.

É necessário ter claro que o governo estadual não é o único ator envolvido na governança da água em São Paulo. De fato, outros atores centrais participam (ou deveriam participar) desse processo. Os governos municipais têm gerência sobre importantes políticas relacionadas à água (resíduos sólidos, uso e ocupação do solo, etc), e mesmo assim muitos deles estão se ausentando do debate sobre essa situação ou até mesmo tomando medidas que impactam negativamente a qualidade da água da região. Os Comitês de Bacia são outro exemplo de atores centrais na governança da água e que pouco apareceram nas notícias sobre $\mathrm{o}$ assunto.

É possível verificar a existência de indicativos substanciais da desgovernança dos recursos hídricos e do não cumprimento da responsabilidade compartilhada no sistema de gestão da água no Brasil. 
A opção feita aqui foi um recorte subjetivo de analisar o posicionamento de determinados atores da esfera estadual. Um dos motivos para essa escolha é decorrente do fato de que grande parte das notícias veiculadas nos meios de comunicação faz referência ao governo estadual, o que gera uma quantidade mais adequada de análise do pesquisador.

Isso posto, este artigo propõe uma revisão dos discursos dos tomadores de decisão, especificamente do (i) Governador do Estado, (ii) Secretário de Saneamento e Recursos Hídricos e (iii) Presidente da Sabesp, nos diferentes momentos acima identificados.

A partir dessa revisão e à luz da contribuição teórica de Joan Subirats, a proposta deste artigo é problematizar se a situação hídrica da RMSP se tornou um problema político na agenda do governo estadual.

Portanto, o contexto da crise hídrica se estabelece numa situação complexa, sistêmica, com grande diversidade de causas e atores. Não obstante, neste artigo a escolha foi de, a partir da contribuição de Joan Subirats, desenvolver uma reflexão a partir de dois recortes: temporal, com início em 2014 até o outubro de 2015; referente aos atores, olhando especificamente para discursos de autoridades do governo estadual, mesmo que esse não represente o único ator responsável pela gestão dos recursos hídricos.

\section{REFERENCIAL TEÓRICO}

O conceito de problema pode ter determinadas variações de significado. Especificamente para este artigo, o propósito é considerar o termo no âmbito das políticas públicas, vale dizer, investigar quando um determinado assunto se torna de fato um problema e entra para o rol de prioridades dos tomadores de decisão. Nesse sentido, a produção científica de Joan Subirats permite identificar uma série de elementos em termos de definição, os fatores de causa e os impactos de um problema nas políticas públicas, contribuindo especificamente para a análise do caso hídrico de São Paulo.

Joan Subirats é teórico espanhol, doutor em ciências econômicas e professor de ciência política na Universidade Autônoma de Barcelona. Seus temas de pesquisa são governança, gestão pública e análise de políticas públicas. Foi fundador e diretor do Instituto de Gobierno y Políticas Públicas (IGOP) da mesma universidade. 
ANALISE DA GESTÃO HÍDRICA EM SÃO PAULO À LUZ

DO REFERENCIAL DE JOAN SUBIRATS

De início, Subirats (2006) esclarece que os problemas são realidades socialmente construídas. Ou seja, não é possível elencar fatores puramente objetivos para definir o que é ou o que não é um problema no mundo das políticas públicas. Essa definição está diretamente atrelada à avaliação dos atores envolvidos na situação. Determinados atores-chave, segundo suas perspectivas e valores, reconhecem ou não uma determinada situação enquanto problema.

Essa avaliação do autor fornece elementos significativos para compreender que Subirats (2006) se aproxima de uma perspectiva teórica que considera os aspectos subjetivos, e que, portanto, não entende a produção científica como sendo algo puramente objetivo. O que decorre desse caráter subjetivo é a dificuldade em estabelecer limites claros para um problema, e dependendo de uma avaliação social subjetiva.

Uma das características dos problemas em políticas públicas destacadas pelo cientista espanhol é o fato de que, na grande maioria das vezes, os problemas de determinado setor guardam relação estreita com problemas de outras áreas. O exemplo destacado em seu artigo destaca a relação entre os problemas das áreas de transportes, meio ambiente, energia e emprego. (SUBIRATS, 2006).

Tendo em vista que o problema é uma construção analítica dependente da subjetividade dos atores envolvidos, Subirats (2006) avança em sua argumentação para tentar estabelecer o que é um problema. Para tal, considera as contribuições de David Dery (1984) em sua obra Problem definition in policy analysis. Dery é cientista política pela Hebrew University of Jerusalem e mestre e doutor em política pública pela UC Berkeley.

Subirats (2006), ao resgatar a produção do professor israelense, reafirma que o $1^{\circ}$ passo para que uma determinada situação se transforme em um problema público é seu reconhecimento. Reconhecer a gravidade de uma realidade permite avançar para que soluções sejam consideradas e ações públicas sejam implementadas. Em outras palavras, reconhecer um problema em políticas públicas está diretamente vinculado à oportunidade de superá-lo.

O reconhecimento, portanto, é uma condição necessária para que as demais etapas no âmbito das políticas públicas possam ocorrer. A figura exposta no trabalho de Subirats (2006) ilustra as etapas que o problema precisa percorrer para de fato ser objeto de transfor- 
mação social. Em primeiro lugar, o reconhecimento enquanto problema, em seguida garantir que o problema traz consigo os elementos que façam com que ganhem relevância pública, e, por fim, a atuação empírica e a transformação social a partir de políticas públicas.

Figura 1 - Processo de formação da agenda institucional

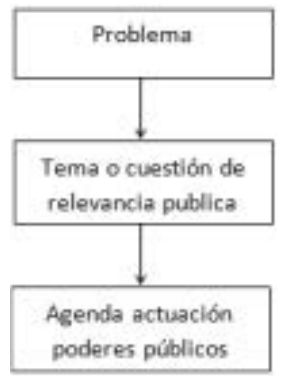

Fonte: SUBIRATS, J. Definición del problema. Relevancia pública y formación de la agenda de actuación de los poderes públicos. In: SARAVIA, E.; FERRAREZI, E. (Orgs.). Políticas públicas, coletânea. Brasília: ENAP, 2006. v.1, p. 205.

Para que um problema ganhe relevância pública, Subirats (2006) elenca uma série de elementos que normalmente devem ser garantidos, de modo que a agenda possa então avançar. Entre eles estão a observação dos recursos financeiros e humanos para tratar do problema, a legislação vigente, a vontade política e as pressões por parte da sociedade e da mídia. Caso algum desses elementos não esteja contemplado, existe uma possibilidade real de que o problema não seja incorporado à agenda de atuação dos poderes públicos.

Ainda assim existem algumas ocasiões que podem influenciar de modo a pressionar para que um determinado problema avance. Entre elas, o autor destaca as situações de crise, elementos muito peculiares e situações de comoção emocional. Em paralelo, existem igualmente alguns atores ou grupos de atores com a capacidade de influenciar diretamente a tomada de decisões, denominados de agenda setters, como por exemplo, partidos públicos, grupos organizados, ONGs e grupos de lobby. Entretanto, nenhum desses elementos, por si só, garante a politização de determinado assunto.

Dessa forma, para que uma situação se torne um problema é necessário que ganhe visibilidade e que os tomadores de decisão a interpretem como sendo suficientemente relevante. "Por tanto, nos encontramos ante una cierta competencia entre cuestiones o temas 
planteados, ante la cual los poderes públicos establecerán prioridades, outorgando status de 'problema público' a determinados temas y no a otros." (SUBIRATS, 2006, p. 205, grifo do autor).

Por fim, Subirats (2006) destaca que para que uma situação se torne de fato um problema público, o reconhecimento deve vir de um agente público com legitimidade para tratar daquele assunto específico. Ou seja, é imprescindível que haja uma definição oficial do problema. "El paso de un tema o cuestión de relevancia pública a la consideración de 'asunto público a resolver' y, por tanto, a su inclusión en el programa o agenda de actuación de los poderes públicos implica uma cierta 'definición oficial' del problema a resolver." (SUBIRATS, 2006, p. 209-210).

É sob essa perspectiva, e considerando os aportes teóricos de Joan Subirats, que a próxima seção deste artigo avança para analisar o caso de São Paulo e a situação de seu abastecimento público durante os anos de 2015 e 2016. As contribuições teóricas em termos de definição, etapas e atores envolvidos na construção de um problema público permitem analisar o caso e verificar as condições da agenda hídrica paulista e o posicionamento dos responsáveis pela mesma.

Portanto, este artigo propõe relacionar o conceito de problema de política pública de Subirats ao contexto da crise hídrica de São Paulo. Joan Subirats (2006) considera que uma situação torna-se um problema de política pública quando cumpre dois aspectos: essa situação ganha visibilidade na sociedade e os tomadores de decisão aceitam que ela representa um problema.

A situação da gestão hídrica em São Paulo claramente já ganhou expressiva notoriedade no debate público. Em recente pesquisa do Instituto Democracia e Sustentabilidade (IDS) e do Instituto de Energia e Ambiente (IEE) da Universidade de São Paulo (USP), foram mapeadas 503 notícias veiculadas em três jornais com grande circulação (Folha de São Paulo, O Estado de São Paulo e O Globo), sem considerar as notícias que informavam apenas a alteração dos níveis dos reservatórios. (UNIVERSIDADE DE SÃO PAULO; INSTITUTO DEMOCRACIA E SUSTENTABILIDADE, [20--?]). Tal número permite verificar com apoio quantitativo a expressividade do assunto.

Uma vez que os discursos representam a principal fonte para o desenvolvimento das análises, o referencial metodológico da aná- 
lise do discurso foi igualmente incorporado ao instrumental utilizado por este autor. Essa escolha metodológica inserida no campo da linguística permitiu observar de maneira detalhada como os atores-chave da governança hídrica paulista se posicionaram tanto na forma oral quanto escrita.

O professor e linguista brasileiro José Luiz Fiorin (1990), em sua obra Tendências da análise do discurso, destaca o fato de que a análise do discurso não trata somente dos aspectos puramente linguísticos, mas deve considerar igualmente o contexto histórico em que o discurso está inserido. É nesse sentido que este artigo desenvolve as análises, ao analisar os discursos considerando o emissário do mesmo, seus interlocutores e sua temporalidade e contexto.

Portanto, a proposta deste artigo é desenvolver uma análise a partir do segundo critério posto por Subirats (2006): a aceitação das autoridades de que determinada situação representa um problema de política pública. Nesse sentido, a partir dos discursos dos tomadores de decisão do governo estadual, a investigação propõe esclarecer se a situação hídrica paulista se tornou ou não um problema.

Da mesma maneira como Subirats (2006) aponta que a definição de problema é resultado de uma leitura subjetiva do analista, as conclusões desse artigo representam uma possível narrativa para compreender a gestão dos recursos hídricos em São Paulo. Conforme o linguista Fiorin (1990, p. 1, grifos do autor) esclarece, "[...] a análise do discurso não busca 'o' sentido verdadeiro do texto, nem 'o' seu sentido oculto, nem 'a' interpretação inédita [...]", mas representa uma possibilidade de leitura intrinsecamente vinculada aos valores e ideais de quem a realiza.

\section{A GESTÃO DOS RECURSOS HÍDRICOS EM SÃO PAULO TORNOU-SE UM PROBLEMA DE POLÍTICA PÚBLICA?}

\subsection{Considerações iniciais}

Nesta seção do artigo a construção do raciocínio se dará da seguinte maneira: serão selecionados de maneira não exaustiva e apresentados segundo a linha cronológica dos fatos os discursos dos gestores de três órgãos estaduais responsáveis diretamente na governança dos recursos hídricos. Sob este conteúdo será desenvolvido o 
ANALISE DA GESTÃO HÍDRICA EM SÃO PAULO À LUZ

DO REFERENCIAL DE JOAN SUBIRATS

exercício de, a partir do referencial teórico de Joan Subirats, tentar verificar se em determinado momento existe alguma declaração com suficiente peso e legitimidade que possibilite afirmar que a situação dos recursos hídricos em São Paulo é reconhecida por estes policy makers como problema.

Como já dito anteriormente, para compreender os discursos e ações do ano de 2014 é necessário ter em mente que no mês de outubro de 2014 aconteceram os dois turnos das eleições. Esse momento gera impactos diretos e indiretos nos acontecimentos anteriores e posteriores. O Governador Geraldo Alckmin foi reeleito em outubro com 57\% dos votos e em janeiro de 2015 nomeou novos gestores da Sabesp e da Secretaria de Saneamento e Recursos Hídricos (SSRH).

Dessa forma, com o intuito de manter um rigor nas comparações, durante o ano de 2014 serão destacadas somente declarações do Governador do Estado de São Paulo. A partir do ano de 2015 são inseridos na análise os discursos de Jerson Kelman (Presidente da Sabesp) e Benedito Braga (Secretário de Saneamento e Recursos Hídricos), nomeados no inicio de janeiro.

Outra observação importante é a respeito da Sabesp. Instituição de capital misto, responsável pelo fornecimento de água, coleta e tratamento de esgotos de 364 municípios. O Governo do Estado de São Paulo é o acionista majoritário da Sabesp. Portanto, a Sabesp é considerada aqui como organização pública.

\subsection{Análise das declarações dos gestores públicos}

O ano de 2014 é composto por importantes momentos na compreensão do contexto da crise hídrica. Os acontecimentos são diversos tais como o racionamento drástico de fornecimento de água em Itu, as respostas e reclamações de determinadas populações, a criação do Comitê Anticrise, o conflito entre os estados de São Paulo e Rio de Janeiro pela transposição do Paraíba do Sul, o uso das duas cotas de reserva técnica (volume morto) e a criação da coalizão de organizações da sociedade civil, Aliança pela Água.

No que se refere aos discursos do Governador Geraldo Alckmin, que possibilitam construir uma narrativa do posicionamento deste gestor, é possível destacar três importantes momentos durante o ano de 2014. 
Em fevereiro de 2014, o Governador deu a seguinte declaração a respeito da possibilidade de racionamento no abastecimento:

\begin{abstract}
A economia começou (na primeira semana) com 500 litros por segundo, ou seja, meio metro cúbico por segundo, e agora (na segunda semana) chegamos ao recorde de 2,12 metros cúbicos por Segundo. [...] Então a economia 2,12 metros cúbicos por segundo permite abastecer uma cidade como Osasco ou São José dos Campos apenas com o uso racional da água [...] Se tivermos uma boa colaboração da população contendo o uso racional da água, eu espero que não (haja necessidade de ocorrer racionamento). [...] Nós devemos ter alguns dias de pouca chuva e, a partir do fim de semana, chuvas intensas. Agora precisa ver onde cai a chuva. (LARA, 2014).
\end{abstract}

Em julho de 2014, já havia iniciado a utilização da $1^{\mathrm{a}}$ cota do volume morto do sistema Cantareira o qual operava com 1,8\% de seu volume útil. Nesse contexto, a declaração do Governador foi a respeito da possibilidade de multa por desperdício destinada aos usuários: "Eu não vejo necessidade mais (da multa) porque nós estamos com $91 \%$ da população que aderiu ao uso racional da água. Quase metade, mais de $40 \%$, ganhou o bônus. Mas é a Arsesp (Agência Reguladora de Saneamento e Energia do Estado de São Paulo) que decide." (LEITE; CHAPOLA, 2014).

Em novembro de 2014, num momento pós-eleição, a partir do qual o Governador sai fortalecido politicamente, o Governador muda um pouco seu discurso sobre a situação hídrica em São Paulo. A declaração abaixo citada é do dia 10 de novembro e logo no dia 17 deste mesmo mês é iniciada a utilização da $2^{\mathrm{a}}$ cota do volume morto do sistema Cantareira, que operava com cerca de $-17,1 \%$ de sua capacidade. Nesta declaração o Governador informa a respeito das obras de busca por água mais longe e um possível fluxo de financiamento destas pelo governo federal:

O que nós propusemos ao governo federal foram novas obras, oito obras, e o valor dessas obras será de R $\$ 3,5$ bilhões, o orçamento total das obras. [...] O governo de São Paulo precisará do máximo que [o governo federal] puder. Pode ser recurso a fundo perdido, do Orçamento Geral da União, ou pode ser financiamento, e nós temos uma boa capacidade de financiamento [...] Não há esse risco [de racionamento]. Nós já temos repetido isso desde o início do ano, nós temos em São Paulo um sistema extremamente forte e nós nem entramos na segunda reserva técnica do Cantareira. (MATOSO; CALGARO, 2014). 
ANALISE DA GESTÃO HÍDRICA EM SÃO PAULO À LUZ

DO REFERENCIAL DE JOAN SUBIRATS

A análise desses três discursos permite verificar que até o final do ano de 2014 não havia um reconhecimento e aceitação por parte do Governador de que a situação dos recursos hídricos em São Paulo representava um problema de política pública. Estes discursos permitem verificar algumas características: a falta de chuva enquanto causa, a responsabilidade da população para resolução daquela situação e a falta de alinhamento entre os posicionamentos do Governador e as ações dos operadores dos sistemas de abastecimento. Em nenhum momento a capacidade de resolução da situação é considerada sob a responsabilidade dos policy makers.

A partir de janeiro de 2015 entram no escopo dois atores que compõem o objeto de análise, os recém-empossados: Benedito Braga, Secretário de Saneamento e Recursos Hídricos e Jerson Kelman, Presidente da Sabesp.

Logo no primeiro dia do ano de 2015, Benedito Braga fala a respeito da estratégia de controle da demanda a partir de política tarifária.

Em um mês ou dois nós vamos avaliar se essa medida da tarifa adicional vai surtir o resultado que nós estamos querendo ou não [...] Vamos ver como é que essa opção reage, porque, no fundo, não estamos querendo aumentar tarifa, queremos reduzir o consumo. Então, vamos observar o processo durante um mês ou dois a partir da implementação, e, a partir dessa observação, tomar medidas mais, digamos, de maior incentivo. (LEITE; GADELHA, 2015).

Dois dias após, no dia 3 de janeiro de 2015, Kelman discursa a respeito da necessidade de obras no curto prazo e acaba exaltando a criticidade da situação ao falar em ações de guerra.

Tanto a ligação das Represas Jaguari e Atibainha como o São Lourenço são obras que não resolvem a situação de 2015, mas são absolutamente emergenciais e têm de ser tratadas, na medida do possível, como ações de guerra. Precisamos cortar todos os atalhos que puderem ser utilizados para que elas sejam entregues no prazo mais curto possível. (LEITE, 2015).

Nos primeiros discursos desses dois importantes atores na gestão da água em São Paulo, é possível verificar algumas características interessantes. Enquanto o Secretário de Recursos Hídricos dá atenção a medidas de controle da demanda, portanto interessado no lado do consumo, o Presidente da Sabesp está preocupado com o lado da necessidade de aumentar a oferta de água por meio de obras. 
Chama atenção o conteúdo da fala de Jerson Kelman a respeito da emergência e necessidade de ações de guerra, o que dá abertura para compreender que para esse ator a situação de fato era crítica e precisava ser aceita como um problema de política pública. É interessante analisar o conteúdo e tom dos discursos futuros desse ator, com o objetivo de verificar se é mantida essa interpretação emergencial a respeito da situação.

Nesse momento, em janeiro de 2015, o Sistema Cantareira operava na $2^{\mathrm{a}}$ cota de seu volume morto e contava com $-22,1 \%$ de sua capacidade.

Na data de 14 de janeiro de 2015, o Governador Geraldo Alckmin dá declaração pouco clara a respeito das definições de termos como racionamento e restrição hídrica.

\begin{abstract}
O racionamento já existe. Quando a ANA (Agência Nacional de Águas) diz que você tem de reduzir de $33\left(\mathrm{~m}^{3}\right.$ por segundo) para 17 no Cantareira, é óbvio que há uma restrição hídrica [...] não tem racionamento no sentido de 'fecha o sistema e abre amanhã [...] Isso não tem nem deve ter. Agora, restrição hídrica, claro que tem. (RIBEIRO, VALLE; LEITE, 2015, grifo dos autores).
\end{abstract}

Nesta mesma data de janeiro, Kelman também fala sobre a existência ou não de racionamento e o que a política de redução de pressão impacta na situação do abastecimento hídrico em São Paulo. "Aquela pessoa que não tem água em casa, com toda razão, vai dizer que há racionamento. Mas é uma minoria. Se isso acontece por mais de 24 horas, nós precisamos corrigir. Temos de minimizar o máximo intervalo sem água. E vai acontecer de mais pessoas ficarem menos tempo sem água." (RIBEIRO; VALLE; LEITE, 2015).

A partir dessas declarações desses dois atores é possível desenvolver uma leitura a respeito do quanto essa situação a que eles se referem foge da alçada de suas capacidades. Enquanto o Governador do Estado de São Paulo faz referência a um órgão federal, o Presidente da Sabesp (empresa mista controlada pelo governo estadual de São Paulo) foca seu discurso na percepção da sociedade a respeito da situação. Nesse momento, a política pública que está no centro do debate é a redução de pressão nos sistemas de abastecimento, a qual é gerenciada pela própria Sabesp. No entanto há pouca clareza sobre o que de fato essa ação representa, quais impactos ela gera e a importância da mesma. 


\title{
ANÁLISE DA GESTÃO HÍDRICA EM SÃO PAULO À LUZ DO REFERENCIAL DE JOAN SUBIRATS
}

Sob a perspectiva temporal, notam-se algumas alterações no teor dos discursos. Em novembro de 2014 Alckmin afirmava a impossibilidade de haver racionamento, enquanto que em janeiro de 2015 sua interpretação da situação se altera para o que qualifica como restrição hídrica.

Em fevereiro de 2015, Benedito Braga, Secretário de Saneamento e Recursos Hídricos escreve artigo na Folha de São Paulo.

\begin{abstract}
A região Sudeste enfrenta sua pior crise hídrica da história. Em particular, a área do sistema Cantareira não tem um verão como 2015 desde que os dados de chuva começaram a ser registrados pelo Instituto Agronômico de Campinas, há 125 anos [...] A Secretaria de Saneamento e Recursos Hídricos, por meio do DAEE (Departamento de Águas e Energia Elétrica) e da Sabesp, está agindo para coibir a retirada de água dos rios por usuários não autorizados e priorizando o uso para abastecimento humano. Está também aumentando a segurança hídrica por meio de obras emergenciais, e de médio e longo prazo. O momento é grave e os riscos são grandes. A colaboração de toda a população economizando água ao máximo é essencial para que, em conjunto com as ações de governo, possamos superar essa crise. (BRAGA, 2015).
\end{abstract}

Durante seu primeiro mês de mandato é notória a mudança em seu discurso e na visão acerca da situação. Nesse momento Braga deixa clara sua interpretação de que a situação é de crise hídrica. Não obstante, sua leitura coloca os baixos níveis pluviométricos como causa para a situação dos recursos hídricos. Ao indicar que a causa para as dificuldades de abastecimento seja exclusivamente a falta de chuva, os gestores eximem a centralidade que as políticas públicas exercem para prevenir e mitigar impactos dessa magnitude.

Novamente, a sociedade é incorporada ao discurso como parte da solução, sem explicitar com detalhes como essa colaboração poderia ocorrer, se seria por ação espontânea ou se a partir de políticas de gestão de demanda.

Em março de 2015, Benedito Braga fala sobre as perspectivas de chuva na região dos mananciais de São Paulo e sua interpretação da situação.

Se nós chegarmos ao nível zero do volume útil no início de abril, as chances de mudarmos o sistema que temos hoje de consumo é praticamente zero [...]. Não há boas perspectivas climatológicas até maio [...]. Estamos com um controle um pouquinho melhor da situação, mas ainda não chegamos ao térreo do reservatório. $\mathrm{O}$ 
próximo trimestre será seco. Temos de estar preocupados. (VENCESLAU; LEITE, 2015).

Nota-se mais uma vez a referência ao fenômeno climatológico. É importante perceber que a partir da leitura de que o problema é a falta de chuva e a situação vivenciada é fruto da falta de chuva, e em se tratando de um fenômeno natural, as políticas públicas pouco podem contribuir para resolver ao mesmo tempo que pouco participaram na construção da situação-problema.

Braga expõe sua carga de preocupação, mas não relaciona a situação às capacidades de intervenção e resolução das políticas públicas. No mês de março de 2015 o Sistema Cantareira saiu da $2^{\mathrm{a}}$ cota do volume morto e retornou à $1^{\mathrm{a}}$ cota, com $-17,7 \%$ de sua capacidade. De fato, a situação era preocupante.

No dia 1 de abril de 2015, Jerson Kelman da Sabesp fala sobre as formas de racionamento. "Uma delas é o rodízio. Outra é redução de pressão, outra é dar cotas para os consumidores. Nós não estamos em rodízio." (PORTO, 2015).

No dia 2 de abril de 2015, Alckmin reafirma que não haverá rodizio: "Não há nenhum racionamento [...]. Não há e não haverá rodízio." (PORTO, 2015).

Kelman compreende que existem diversas maneiras de haver racionamento no abastecimento público. Dentre essas possibilidades de racionamento estão a redução da pressão na tubulação e a emissão de cotas para os consumidores. Sendo estas ações postas em práticas pela gestão paulista, a conclusão é de que para Kelman há um racionamento.

O baixo consenso e alinhamento entre os atores estratégicos na gestão da água impossibilita alcançar a característica necessária colocada por Subirats (2006) para que uma situação se torne um problema de política pública: a aceitação dos tomadores de decisão de que a situação é um problema.

No dia 18 de agosto de 2015 há um importante ponto de inflexão na narrativa a partir da publicação no Diário Oficial do Estado de São Paulo a Portaria do Departamento de Águas e Energia Elétrica (DAEE) n $n^{\circ} 2167$, de 17 de agosto de 2015. A partir desse documento é decretada oficialmente a situação de crise hídrica. "Art. $1^{\circ}$ - O DAEE declara em situação de criticidade hídrica a região da bacia hidrográfica do Alto Tietê." (SÃO PAULO, 2015). 
ANALLISE DA GESTÃO HÍDRICA EM SÃO PAULO À LUZ

DO REFERENCIAL DE JOAN SUBIRATS

Em agosto de 2015, o Sistema Alto Tietê operava com 13,8\% de sua capacidade. O Sistema Cantareira operava com $-13,7 \%$ de sua capacidade.

Do ponto de vista do propósito deste artigo, poder-se-ia interpretar que a partir desse momento, com a publicação de um documento oficial, a situação dos recursos hídricos em São Paulo torna-se de vez um problema de política publica. A partir de um olhar mais apurado para o conteúdo da portaria nota-se que este documento serve como gatilho para tomadas de decisão mais rápidas e que não passem por todos os mecanismos de checks and balances. Em seu artigo $1^{\circ}$, parágrafo único: "Pela gravidade da situação de armazenamento dos reservatórios do Sistema Produtor Alto Tietê, com risco para o abastecimento público, ações de caráter especial deverão ser adotadas visando a assegurar a disponibilidade hídrica de modo seguro e eficiente." (SÃO PAULO, 2015, grifo nosso).

Não obstante, ao retomar o mecanismo adotado neste trabalho e analisar os discursos dos agentes, a leitura sobre aquele momento é diferente. Em 19 de agosto de 2015, um dia após a publicação da portaria supramencionada, o Governador Geraldo Alckmin dá a seguinte declaração: "A portaria tem o objetivo de claro de alertar dizendo: 'olha, nós estamos sobre uma crise hídrica, não tem chovida e é preciso, então, ter o esforço coletivo de todos. [...] [A portaria é] burocrática, normal do DAEE." (BORLINA FILHO, 2015).

Notam-se na declaração de Alckmin dois aspectos recorrentes durante o histórico analisado. A situação é resultado da falta de chuva e, portanto, foge da capacidade de intervenção das políticas públicas. A sociedade é chamada para compor enquanto parte da solução.

A respeito de situações de crise, Subirats (2006) dá importante contribuição de como esse qualificativo pode contribuir para que a situação se torne um problema público e entre na agenda.

\footnotetext{
En líneas generales, podría afirmarse que un nuevo tema resulta susceptible de convertirse en 'problema público' y, por tanto, llegar a formar parte del programa de actuación si el tema o cuestión ha alcanzado proporciones de 'crisis' y, por tanto, no puede continuar siendo ignorado. Una lectura detallada de muchas exposiciones de motivo de las leyes podría reafirmarnos en lo expuesto. Otra posibilidad es que el tema plantee claras posibilidades de agravamiento en el futuro, con lo que se pretende anticiparse a la previsible situación de crisis (por ejemplo, residuos nucleares). (SUBIRATS, 2006, p. 205, grifo do autor).
} 
Ainda que determinados elementos contradigam a narrativa, tais como as ações postas em prática pelo governo estadual (obras, redução de pressão, interligação de sistemas) e a portaria do DAEE, do ponto de vista da análise dos discursos desses três tomadores de decisão não é possível verificar uma aceitação oficial legítima de que a situação dos recursos hídricos em São Paulo represente um problema de política pública.

O que significa que, a partir da definição conceitual de Joan Subirats é possível afirmar que a gestão hídrica em São Paulo não representa um problema de política pública para o governo estadual. Possivelmente, essa conclusão auxilie para compreender os motivos da ausência de políticas públicas de longo prazo e estruturais que possam de fato solucionar a situação-problema da água em São Paulo.

\section{CONCLUSÃO}

Na posição de pesquisador, este autor se coloca na posição de analista das declarações acima mencionadas e a partir destas entende que não há um conjunto de declarações que possibilite verificar a natureza problemática da situação da gestão dos recursos hídricos em São Paulo. Mesmo com a Portaria do DAEE em agosto de 2015, que congrega um status oficial de situação de criticidade hídrica, sob o ponto de vista dos discursos dos três atores selecionados (Geraldo Alckmin - Governador do Estado de São Paulo, Benedito Braga - Secretário Estadual de Saneamento e Recursos Hídricos e Jerson Kelman - Presidente da Sabesp) não é possível afirmar que essa situação da gestão da água em São Paulo seja um problema de política pública e que ela esteja de fato na agenda política do governo do estado. "El passo de un tema o cuestión de relevância pública a la consideración de 'asunto público a resolver' y, por tanto, a su inclusión em el programa o agenda de actuación de los poderes públicos implica una cierta 'definición oficial' del problema a resolver." (SUBIRATS, 2006, p. 210, grifo do autor).

Essa é uma das leituras possíveis de ser elaborada a partir dessa narrativa. Conforme Subirats (2006) coloca, a própria definição de problema está relacionada ao julgamento subjetivo do analista de políticas públicas. "Deberemos 'construir', estrutura nuestra propia (la del analista) definición del problema a plantear y resolver" (SUBIRATS, 2006, p. 200, grifo do autor). 
ANALLISE DA GESTÃO HÍDRICA EM SÃO PAULO À LUZ

DO REFERENCIAL DE JOAN SUBIRATS

Os resultados deste artigo permitem elucubrar sobre os apontamentos que podem refletir na gestão das águas em São Paulo e os cenários que essa realidade implica. A negação e não incorporação do assunto na agenda política implica situações tais quais as vividas até o momento: dependência do regime pluviométrico para saber se São Paulo deverá conviver com as enchentes históricas ou com as mais atuais dificuldades de abastecimento. Outra consequência é a insistência da gestão pública em atuar somente em ações emergenciais e se negar a pensar em planos estratégicos de médio e longo prazo.

\section{Referências}

BRAGA, B. Mudança de paradigma e segurança hídrica. Folha de São Paulo, São Paulo, 11 fev. 2015. Opinião. Disponível em:<http:// www1.folha.uol.com.br/opiniao/2015/02/1588132-benedito-bragamudanca-de-paradigma-e-seguranca-hidrica.shtml $>$. Acesso em: 16 ago. 2016.

COMPANHIA DE SANEAMENTO BÁSICO DO ESTADO DE

SÃO PAULO. Situação dos mananciais. São Paulo, 2003. Disponível em: $<$ http://www2.sabesp.com.br/mananciais/DivulgacaoSiteSabesp. aspx>. Acesso em: 25 ago. 2016.

DERY, D. Problem definition in policy analysis. Lawrence, KA: University Press of Kansas, 1984.

BORLINA FILHO, V. Portaria que reconhece crise hídrica é apenas burocrática, diz Alckmin. Folha de São Paulo, São Paulo, 19 ago. 2015. Cotidiano. Disponível em: <http://www1.folha.uol.com.br/ cotidiano/2015/08/1670736-portaria-que-reconhece-crise-hidrica-eapenas-burocratica-diz-alckmin.shtml>. Acesso em: 16 ago. 2016.

FIORIN, J. L. Tendências da análise do discurso. Cadernos de Estudos Linguísticos, Campinas, SP, v. 19, p. 173-179, jul./dez. 1990.

LARA, G. Chance de racionamento hoje está "totalmente descartada", afirma Alckmin. O Estado de São Paulo, São Paulo, 18 fev.

2014. Disponível em: $<$ http://sao-paulo.estadao.com.br/noticias/ geral,chance-de-racionamento-hoje-esta-totalmente-descartada-afirmaalckmin,1131648>. Acesso em: 16 ago. 2016.

LEITE, F. Sabesp, obras anticrise são ações de guerra. O Estado de São Paulo, São Paulo, 3 jan. 2015. Disponível em: $<$ http://sao-paulo. 
estadao.com.br/noticias/geral,sabesp-obras-anticrise-sao-acoes-deguerra, 1614873>. Acesso em: 16 ago. 2016.

; CHAPOLA, R. Alckmin desiste de multa; volume útil do Cantareira zera. O Estado de São Paulo, São Paulo, 9 jul. 2014. Disponível em: $<$ http://sao-paulo.estadao.com.br/noticias/ geral,alckmin-desiste-de-multa-volume-util-do-cantareirazera,1525985>. Acesso em: 20 ago. 2016.

; GADELHA, I. Secretário propõe tarifa progressiva se multa da água não der resultado. O Estado de São Paulo, São Paulo, 1 jan. 2015. Disponível em: $<$ http://sao-paulo.estadao.com.br/noticias/ geral,secretario-propoe-tarifa-progressiva-se-multa-da-agua-nao-derresultado,1614267>. Acesso em: 20 ago. 2016.

MATOSO, F.; CALGARO, F. Alckmin dis que SP precisa de R\$ 3,5 bi para enfrentar crise daágua. G1, Brasília, DF, 10 nov. 2014. Disponível em:<http://g1.globo.com/sao-paulo/noticia/2014/11/ alckmin-diz-que-sp-precisa-de-r-35-bi-para-enfrentar-crise-da-agua. html >. Acesso em: 25 ago. 2016.

PORTO, G. Não há racionamento nem haverá rodízio, diz Alckmin. O Estado de São Paulo, São Paulo, 2 abr. 2015. Disponível em:<http:// sao-paulo.estadao.com.br/noticias/geral,nao-ha-racionamento-nemhavera-rodizio-diz-alckmin, 1662944>. Acesso em: 16 ago. 2016.

RIBEIRO, B; VALLE, C. do; LEITE, F. Alckmin admite racionamento e Sabesp não descarta rodízio. O Estado de São Paulo, São Paulo, 14 jan. 2015. Disponível em:<http://sao-paulo.estadao.com.br/ noticias/geral,alckmin-admite-racionamento-e-sabesp-nao-descartarodizio,1619921>. Acesso em: 25 ago. 2016.

SÃO PAULO. Secretaria de Saneamento e Recursos Hídricos. Departamento de Águas e Energia Elétrica. Portaria DAEE n⿳⺈ 2617, de 17 de agosto de 2015. Diário Oficial do Estado, São Paulo, 18 ago. 2015. Disponível em:<http://www.daee.sp.gov.br/images/documentos/ outorgaefiscalizacao/Portaria2617.pdf>. Acesso em: 15 jul. 2016.

SUBIRATS, J. Definición del problema. Relevancia pública y formación de la agenda de actuación de los poderes públicos. In: SARAVIA, E.; FERRAREZI, E. (Orgs.). Políticas públicas, coletânea. Brasília: ENAP, 2006. v.1, p. 199-218. 
ANÁLISE DA GESTÃO HÍDRICA EM SÃO PAULO À LUZ DO REFERENCIAL DE JOAN SUBIRATS

UNIVERSIDADE DE SÃO PAULO. Instituto de Energia e Ambiente; INSTITUTO DEMOCRACIA E SUSTENTABILIDADE. Crise hídrica e a mídia. São Paulo, [20--?]. Disponível em:<https:/goo.gl/ W3ob8M>. Acesso em: 20 jul. 2016.

VENCESLAU, P.; LEITE, F. Sabesp está em "penúria hídrica", diz Secretário. O Estado de São Paulo, São Paulo, 2 mar. 2015:

Disponível em: <http://sao-paulo.estadao.com.br/noticias/geral,sabespesta-em-penuria-hidrica-diz-secretario,1642691>. Acesso em: 16 ago. 2016. 
